\title{
Spectrophotometric determination of Sulphamethoxazole Via Charge Transfer Complex Formation Reaction
}

Thabit S. Al-Ghabsha

College of Pharmacy

University of Mosul
Theia'a N. Al-Sabha

Department of Chemistry

College of Education

University of Mosul

\section{Mohammed S. Al-Enizzi}

Department of Chemistry / Education College for Girls

University of Mosul

Received

13 / 09 / 2013
Accepted

$06 / 11 / 2013$

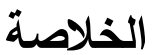

تم وصف طريقة طيفية بسيطة وحساسة لتقدير السلفاميثوكسازول بهيئته النقية وفي مستحضراته الصيد لانية. تعتد الطريقة على تفاعل السلفاميثوكسازول كمادة مانحة للالكترونات

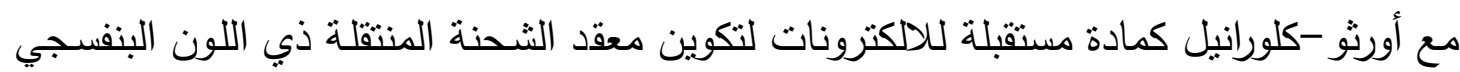

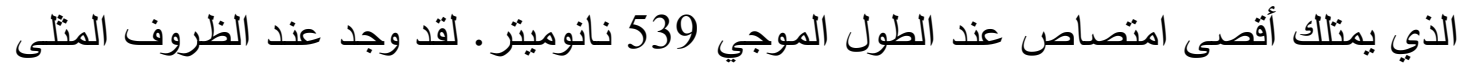

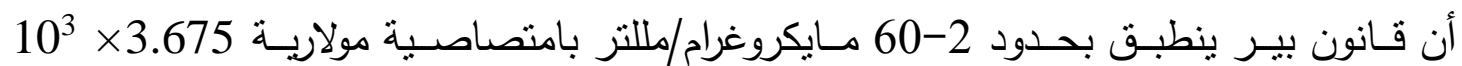

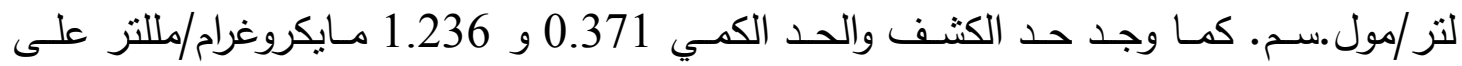

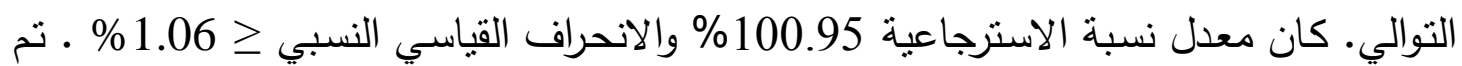

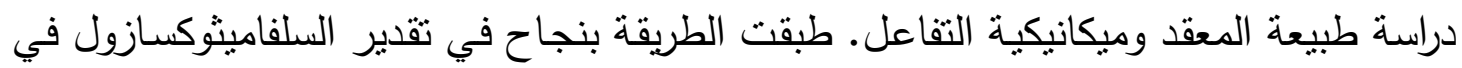

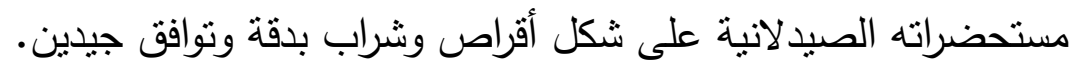

\begin{abstract}
A simple and sensitive spectrophotometric method for the determination of sulphamethoxazole in pure as well as in dosage form is described. The method is based on the reaction of sulphamethoxazole as electron donor with o-chloranil as electron acceptor to form violet colored charge transfer complex having maximum absorption band at $539 \mathrm{~nm}$. Under the optimized reaction conditions, Beer's law was obeyed in the
\end{abstract}


range of 2-60 $\mu \mathrm{g} \mathrm{ml}^{-1}$ with molar absorptivity $3.675 \times 10^{3} \mathrm{~L} \mathrm{~mol}^{-1} \mathrm{~cm}^{-1}$. The limits of detection (LOD) and limit of quantitation (LOQ) were 0.371 and $1.236 \mu \mathrm{g} \mathrm{ml}^{-1}$ respectively. The accuracy and precision of the method were satisfactory; the average recovery $\%$ was $100.95 \%$ and values of relative standard deviations $\leq 1.06 \%$. The stoichiometry of the reaction was studied, and the reaction mechanism was postulated. The proposed method was successfully applied to the determination of sulphamethoxazole in its pharmaceutical tablets and syrup with good accuracy and precisions.

Keywords: Charge transfer; Spectrophotometry; o-chloranil; sulphamethoxazole

\section{Introduction}

Sulfamethoxazole(3-p-aminobenzenesulphonamido-5-methylisoxazole)(SMZ) belongs to the sulfonamides group of chemotherapeutics which using in both systemic and urinary infections. Generally, it is combined with trimethoprim in commercial drugs ${ }^{1,2}$. Numerous methods have been developed for the determination of sulphamethoxazole and trimethoprim in combination present in pharmaceutical preparations ${ }^{3-7}$. Few spectrophotometric methods have been reported for determination of SMZ alone. These methods are based on the reaction of sulphamethoxazole with dimethylaminocinnamaldehyde ${ }^{8}$, 1-2naphthaquinone-4-sulfonate ${ }^{9}, \quad 7,7,8,8$-tetracyanoquinodimethane ${ }^{10}, \quad 1$ naphthol ${ }^{11}$, phenosafranine ${ }^{12}$, phloroglucinol ${ }^{13}$, dopamine in the presence of molybdate ions ${ }^{14}$, p-dimethylaminobenzaldehyde and 8hydroxyquinoline ${ }^{15}$.

The methods that are based on charge-transfer complexation are usually sensitive, rapid and simple to perform. Charge transfer reactions have been widely used for the determination of electron donating compounds through interaction with $\pi$-acceptors.

This work describes a simple, rapid and sensitive spectrophotometric method for the determination of SMZ, in its pure form and pharmaceutical formulations containing trimethoprim and other excepients, by exploiting its electron donating property. The method is based on the charge transfer complexation reaction of SMZ with $o$ chloranil.

\section{Experimental}

\section{Apparatus}

Shimadzu UV-1650 PC UV-Visible spectrophotometer equipped with a 1.0-cm path length silica cell, Philips PW (9421) pH-meter with a combined glass electrode was used for $\mathrm{pH}$ measurements, All calculations in the computing process were done in Microsoft Excel for Windows. Weighing was carried out on a balance type of Mettler H 54 AR.

\section{Chemicals}


Sulphamethoxazol and its pharmaceutical formulations (tablet and syrup) were kindly provided by state company for Drug Industries and Medical Appliance-(SDI) Sammara-Iraq. o-Chloranil was obtained from MOLEKULA and other chemicals were obtained from Fluka and BDH companies. All solvents were analytical reagent grade and water was distilled.

Working standard solution of sulphamethoxazol: $250 \mu \mathrm{gml}^{-1}$ sulphamethoxazole solution was prepared by dissolving of $25 \mathrm{mg}$ of its pure form in $5 \mathrm{ml}$ ethanol and diluted to $100 \mathrm{ml}$ with distilled water in a

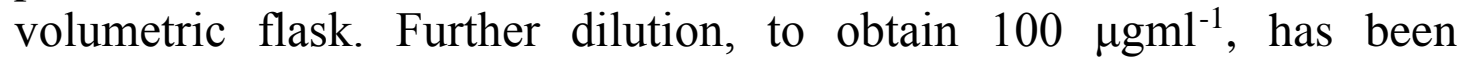
prepared.

Reagent solution: $5 \times 10^{-3} \mathrm{M}$ o-chloranil solution was prepared by dissolving $0.123 \mathrm{~g}$ in absolute ethanol and diluted to $100 \mathrm{ml}$ in a calibrated flask with the same solvent.

Basic solutions: $0.01 \mathrm{M}$ sodium carbonate and sodium hydroxide were prepared in distilled water.

\section{Recommended procedure}

Aliquots of the working solution of sulphamethoxazol $\left(2-60 \mu \mathrm{gml}^{-1}\right)$ were transferred into a series of $5 \mathrm{ml}$ calibrated flasks. Then, $1 \mathrm{ml}$ of $5 \times 10^{-3}$ o-chloranil and $0.75 \mathrm{ml}$ of $0.01 \mathrm{M} \mathrm{Na}_{2} \mathrm{CO}_{3}$ were added and the solutions were diluted to the mark with ethanol. The absorbance was measured at $539 \mathrm{~nm}$ at room temperature against reagent blank.

\section{Procedure for pharmaceutical formulations Tablet}

Ten tablets (each tablet containing $400 \mathrm{mg}$ sulphamethoxazole) were accurately weighed and pulverized. A portion of the fine and homogenized powder equivalent to $400 \mathrm{mg}$ sulphamethoxazol was accurately weighed and dissolved in about $10 \mathrm{ml}$ of water-ethanol (50:50 $\mathrm{v} / \mathrm{v})$ mixture with mixing and heating for $5 \mathrm{~min}$, then filtered with Whatmann filter paper no.1. The filtrate was diluted to the 100 with

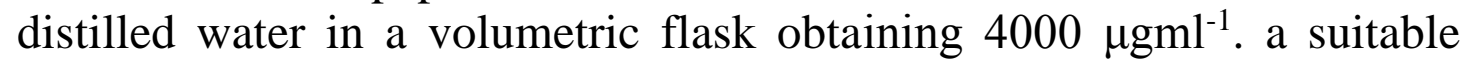
volume was diluted, and the above procedure was followed.

\section{Syrup}

The appropriate volume of the syrup containing SMZ equivalent to $10 \mathrm{mg}$ was transferred into a $100 \mathrm{ml}$ measuring flask, diluted, filtered and made up to the mark with distilled water. An aliquot of the solution was analyzed, as described in recommended procedure.

\section{Results and discussion}


The proposed method involves the and reaction of SMZ with ochloranil reagent in the presence of $\mathrm{Na}_{2} \mathrm{CO}_{3}$ to form a violet colored charge transfer complex having maximum absorption at $539 \mathrm{~nm}$. This wavelength was used for all subsequent measurements. The absorption spectra of the reaction product are shown in Figure 1. The corresponding reagent blank have low absorbance at this wavelength.

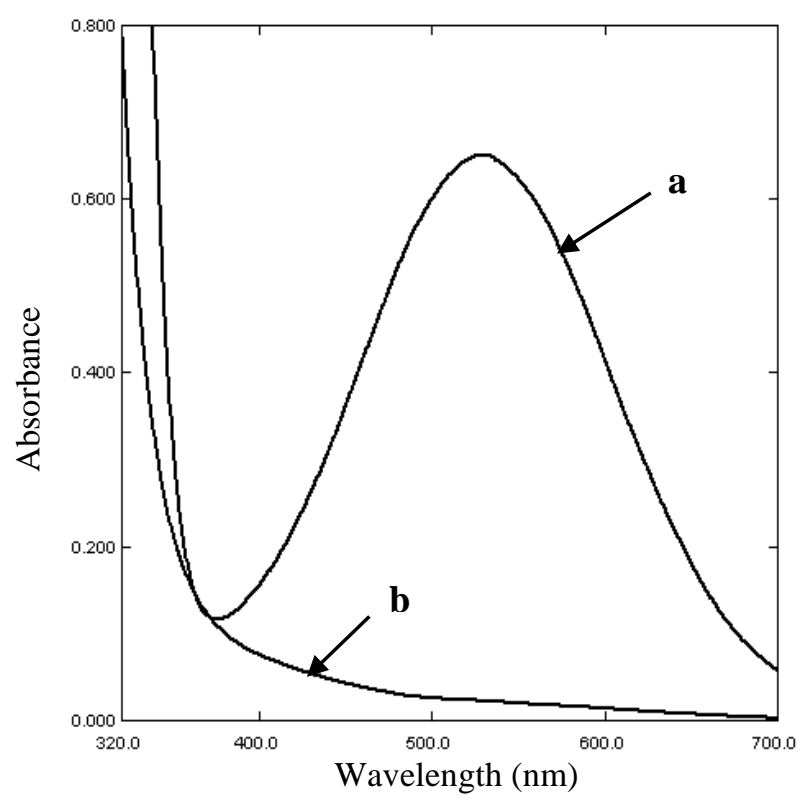

Figure 1: Absorption spectra of (a) SMZ $\left(20 \mu \mathrm{g} \mathrm{ml}^{-1}\right)$ complex with $o$-CA reagent $\left(5 \times 10^{-3} \mathrm{M}\right)$ in the presence of $0.01 \mathrm{M} \mathrm{Na} \mathrm{CO}_{3}$ against reagent blank and (b) reagent blank against distilled water.

\section{Optimization of experimental conditions}

The optimum conditions for the color development of the $o-C A$ SMZ complex were established by varying the parameters one at a time, keeping the others fixed and observing the effect produced on the absorbance of colored species. The following experiments were conducted for this purpose and conditions so obtained were incorporated in general procedure.

\section{Effect of solvents}

Different solvents such as methanol, ethanol, acetonitrile, acetone and water as medium for the reaction, between SMZ $\left(20 \mu \mathrm{gml}^{-1}\right)$ and $o$ $C A\left(1 \mathrm{ml}\right.$ of $\left.5 \times 10^{-3} \mathrm{M}\right)$, in the presence of $\mathrm{NaOH}(1 \mathrm{ml}$ of $0.01 \mathrm{M})$ in final volume of $5 \mathrm{ml}$, have been tried in order to achieve maximum sensitivity and complex stability. The absorbance of solutions were measured against corresponding blank after $5 \mathrm{~min}$ at room temperature. As shown in table1. It was found that on using water as solvent for sulphamethoxazole and ethanol as solvent for $o-C A$ and dilution with 
ethanol were gave maximum color intensity and recommended in this method. However; dilution with water gave turbid solutions.

Table 1: Effect of solvents on the absorbance of $o-C A-S M Z$ complex

* Sample against blank

\begin{tabular}{|cccccc|}
\hline $\begin{array}{c}\text { SMZ } \\
\left(\mathbf{2 0} \boldsymbol{\mu g m l} \mathbf{- 1}^{-1}\right) \\
\text { dissolved in }\end{array}$ & $\begin{array}{c}\boldsymbol{o - C A} \\
\text { Dissolved in }\end{array}$ & $\begin{array}{c}\text { Dilution } \\
\text { by }\end{array}$ & $\begin{array}{c}\boldsymbol{\lambda} \mathbf{m a x} \\
\mathbf{n m}\end{array}$ & Abs. $\mathbf{S}^{*}$ & Abs.B ** \\
\hline Water & Methanol & Water & - & turbid & turbid \\
Water & Methanol & Methanol & - & turbid & turbid \\
Methanol & Methanol & Methanol & 446 & 0.137 & 0.278 \\
Methanol & Methanol & Water & - & turbid & turbid \\
Water & Ethanol & Water & 525 & 0.121 & 0.052 \\
Water & Ethanol & Ethanol & 539.5 & 0.140 & 0.039 \\
Ethanol & Ethanol & Ethanol & 523.5 & 0.092 & 0.084 \\
Ethanol & Ethanol & Water & 367 & 0.110 & 0.411 \\
Water & Acetone & Water & - & turbid & turbid \\
Water & Acetone & Acetone & 541 & 0.118 & 0.058 \\
Acetone & Acetone & Acetone & 553 & 0.014 & 0.055 \\
Acetone & Acetone & Water & 580 & 0.019 & 0.034 \\
Water & Acetonitrile & Water & 445 & 0.082 & 0.106 \\
Water & Acetonitrile & Acetonitrile & 409 & 0.078 & 0.120 \\
Acetonitrile & Acetonitrile & Acetonitrile & 495.5 & -0.014 & 0.093 \\
\hline
\end{tabular}

** Blank against solvent at $\lambda_{\max }$ of complex

\section{Effect of $\mathbf{p H}$}

The effect of $\mathrm{pH}$ on the absorption of the complex was studied using different $\mathrm{pH}$ values. It was observed that the complex was formed with low sensitivity at $\mathrm{pH} 3.34$, but this sensitivity was increased by addition of $\mathrm{NaOH}$ and reached its maximum absorption at $\mathrm{pH} 5.1$ (Fig.2). Therefore different buffers of $\mathrm{pH} 5.1$ were prepared to examine the sensitivity. A negative effect was observed on the color intensity.

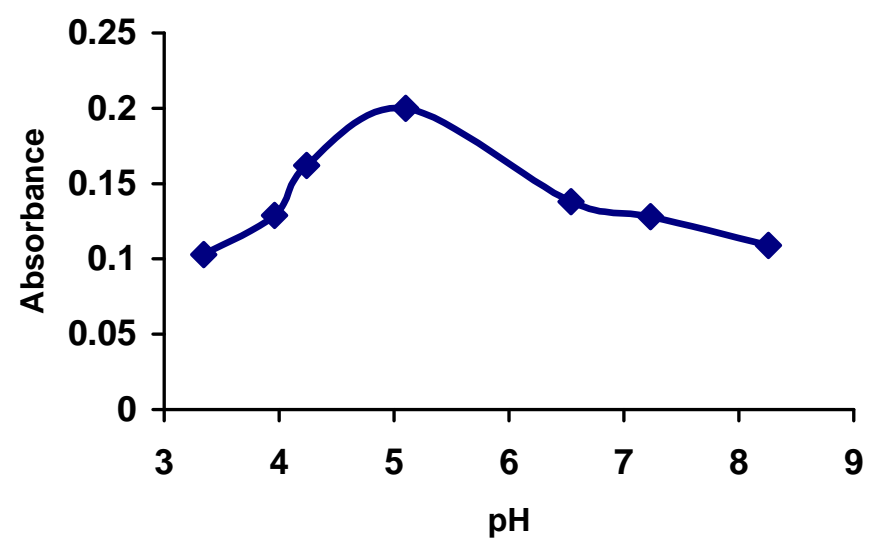

Figure 2: Effect of $\mathrm{pH}$ on the absorption of $20 \mu \mathrm{gml}^{-1} \mathrm{SMZ}$ complex with $\mathrm{o}-\mathrm{CA}$ Effect of bases 
To obtain high sensitivity for the complex, different bases such as sodium hydroxide, potassium hydroxide, sodium carbonate and sodium bicarbonate with fixed volume and a concentration of $0.01 \mathrm{M}$ were examined by addition to a fixed amount of SMZ. It was found that sodium carbonate gave maximum color intensity (Figure 3), and the optimum amounts of this base were found to be $0.75 \mathrm{ml}$ which was used in the subsequent experiments.

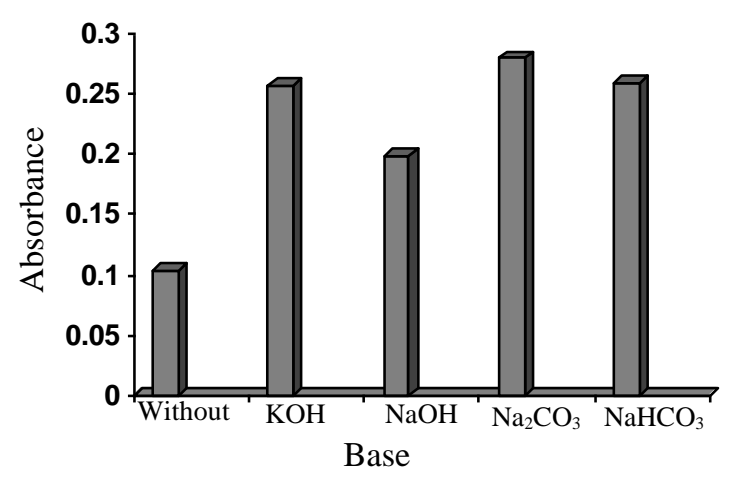

Figure 3: Effect of Different bases on the intensity of $20 \mu \mathrm{gml}^{-1} \mathrm{SMZ}$ complex with $o-C A$

\section{Effect of $o-C A$ concentration}

The effect of changing the $o-C A$ concentration on the absorbance of solution containing a fixed amount of SMZ was studied. It was observed that the absorbance increases with increasing $o-C A$ concentration and reached maximum on using $1.0 \mathrm{ml}$ of $5 \times 10^{-3} \mathrm{M} \mathrm{o-CA}$ (Figure 4). Therefore, this volume of this concentration was used in the subsequent work.

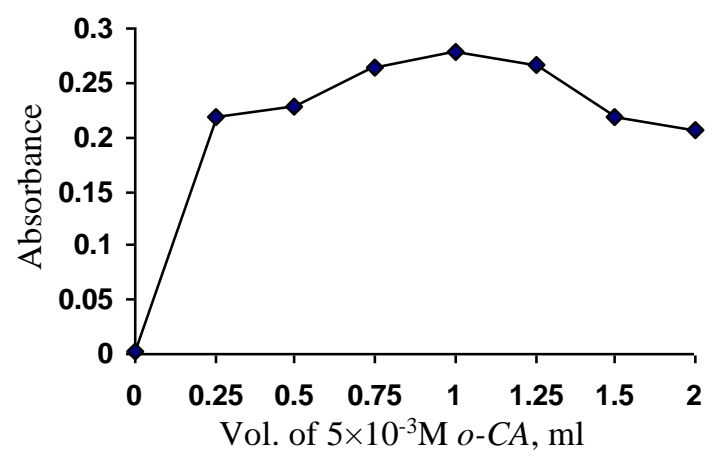

Figure 4: Effect of $o-C A$ reagent concentration on absorbance of $20 \mu \mathrm{gml}^{-1} \mathrm{SMZ}$

\section{Effect of surfactant}

Effect of various surfactants including sodium dodecyl sulphate (SDS), cetylperydinum chloride (CPC), cetyltrimethylammonium bromide (CTAB), Tween- 80 and Triton $\mathrm{x}-100$ were tested. It was found that these surfactants decreased the absorbance of solutions.

Effect of temperature and reaction time 
The reaction time was determined by following the color development at room temperature and in thermostatically controlled water-bath at different temperatures up to $60^{\circ} \mathrm{C}$. The absorbance was measured at 5 and 10 minutes intervals against reagent blank treated similarly. It was observed that the complex was formed after addition of $o-C A$ immediately at room temperature and no effect of high temperatures on the maximum absorbance and stability of the complex $(>5 \mathrm{hr})$, therefore room temperature $\left(25^{\circ} \mathrm{C}\right)$ was selected.

\section{Order of addition}

The order of addition of reactants on the color development was examined. Maximum sensitivity was achieved when SMZ and $o$ - $C A$ were added before adding the sodium carbonate as shown in Fig. 5. Hence, the method was performed in the order: $\mathrm{SMZ}+o-C A+\mathrm{Na}_{2} \mathrm{CO}_{3}$.

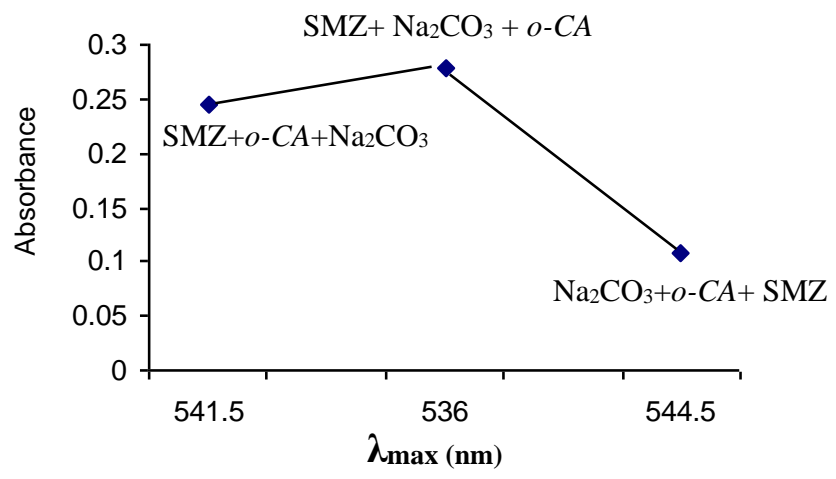

Figure 5: Effect of order of reactants on the absorption of $20 \mu \mathrm{g} / \mathrm{ml} \mathrm{SMZ}$

\section{Quantification}

In order to investigate the range in which the colored complex adhere to Beer's law, the absorbance of the complex was measured at 539 $\mathrm{nm}$ after developing the color by following the general procedure calibration graph for a series of solutions containing increasing amounts of SMZ. The Beer's law limits and molar absorptivity values were evaluated and given in Table 2, which are indicated that the method is sensitive. The linearity was represented by the regression equation and the corresponding correlation coefficient for the studied determined drugs by the proposed method represents excellent linearity. The relative standard deviation (RSD) and accuracy (average recovery \%) for the analysis of five replicates of each three different concentrations for SMZ indicated that the method is precise and accurate. Limit of detection (LOD) are in the accepted range below the lower limit of Beer's law range. 
Table 2: Summary of optical characteristics and statistical data for the proposed method

\begin{tabular}{|c|c|}
\hline Parameter & SMZ \\
\hline Beer's law limits $\left(\mu \mathrm{g} \mathrm{ml}^{-1}\right)$ & $2-60$ \\
\hline Molar absorptivity $\left(1 \cdot \mathrm{mol}^{-1} \cdot \mathrm{cm}^{-1}\right)$ & $3.675 \times 10^{3}$ \\
\hline $\mathrm{LOD}\left(\mu \mathrm{g} \cdot \mathrm{ml}^{-1}\right)$ & 0.371 \\
\hline $\operatorname{LOQ}\left(\mu \mathrm{g} \cdot \mathrm{ml}^{-1}\right)$ & 1.236 \\
\hline Average recovery $(\%)^{*}$ & 100.95 \\
\hline Correlation coefficient & 0.9994 \\
\hline Regression equation $(\mathrm{Y})^{* *}$ & \\
\hline Slope, $a$ & 0.0145 \\
\hline Intercept, $b$ & 0.0101 \\
\hline $\mathrm{RSD}^{\mathrm{a}}$ & $\leq 1.06$ \\
\hline
\end{tabular}

\section{Interference}

The extent of interference by some excipients which often accompany pharmaceutical preparations were studied by measuring the absorbance of solutions containing fixed amount of SMZ and various amounts of diverse species, including trimethoprim which is present the pharmaceutical formulations of SMZ, in a final volume of $5 \mathrm{ml}$. It was found that the studied excipients up to 22.5 fold excess did not interfere seriously (Table 3). However; an error of $5.0 \%$ in the absorbance readings was considered tolerable.

Table 3: Effect of excipients for assay of SMZ

\begin{tabular}{lcccc}
\hline \multirow{2}{*}{ Exciepient } & \multicolumn{4}{c}{$\begin{array}{c}\text { Recovery } \% \text { of } 20 \mu \mathrm{g} / \mathrm{ml} \text { of SMZ per } \\
\mu \mathrm{gml}^{-1} \text { Foreign added }\end{array}$} \\
\cline { 2 - 5 } & 25 & 50 & 100 & 250 \\
\hline Trimethoprim & 97.05 & 98.75 & 97.15 & 99.90 \\
Sodium chloride & 99.90 & 102.90 & 100.03 & 95.55 \\
Arabic Gum & 100.10 & 100.55 & 103.45 & 96.45 \\
Starch & 104.15 & 101.60 & 98.85 & 104.55 \\
Acacia & 98.50 & 104.00 & 102.40 & 96.40 \\
Glucose & 96.95 & 96.15 & 99.00 & 98.65 \\
\hline
\end{tabular}

\section{Stoichiometry, stability constant and mechanism}

The molar ratio of the $n-\pi$ charge transfer complex formed between the SMZ and $o-C A$ reagent was investigated by applying the continuous variation (Job's) and mole ratio methods [16]. The results indicated that 
complex was formed in the ratio of 1:1 (Figures 6). This finding supports that the $n-\pi$ CT complex is formed through amino group. The stability constant $\left(\mathrm{K}_{\mathrm{st}}\right)$ of the complex was determined according to the previous ratio and found $1.897 \times 10^{3} 1 . \mathrm{mol}^{-1}$. However; the probable reaction mechanism based on the reported method ${ }^{[17]}$ is given in scheme 1 .
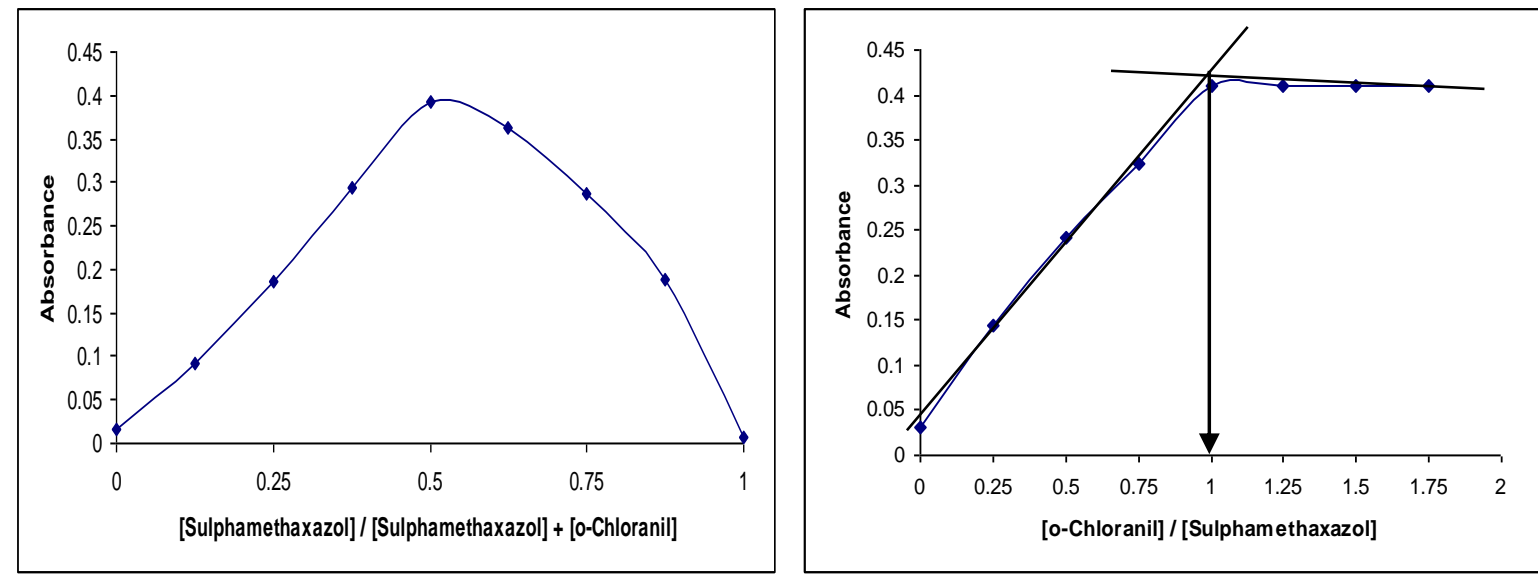

Figure 6: Continuous variations and mole ratio plots for complex of SMZ $\left(1.5 \times 10^{-3} \mathrm{M}\right)$ and $o-C A\left(1.5 \times 10^{-3} \mathrm{M}\right)$ under the optimum reaction conditions.

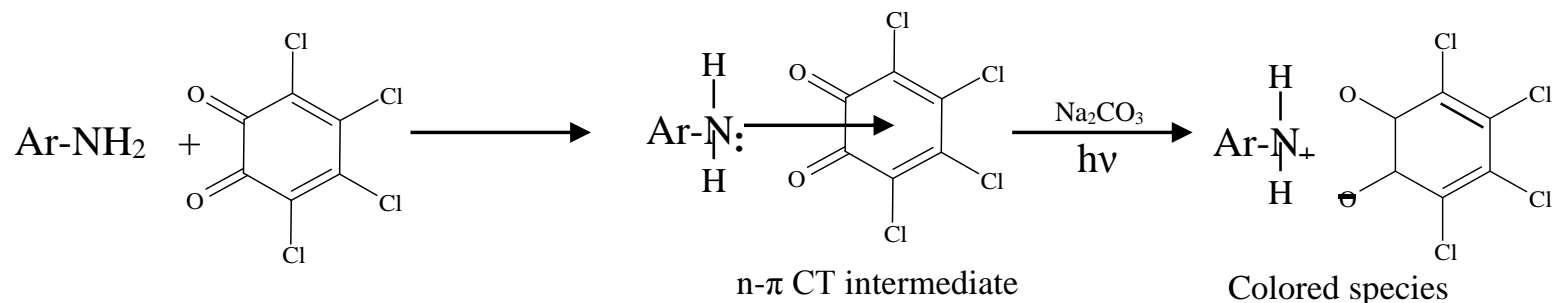<smiles>Cc1cc(NS(=O)(=O)c2ccc(N)cc2)no1</smiles>

Scheme 1: Probable mechanism for the reaction of $o$-CA with SMZ

\section{Analytical applications}

The proposed method was successfully applied to determine SMZ in pharmaceutical tablets and syrup preparations. The validity of the method was confirmed by applying the standard addition procedure, (Fig.7) and the results suggested that there is no interference from any excipients, which are present in commercial dosage forms, Table 4. 

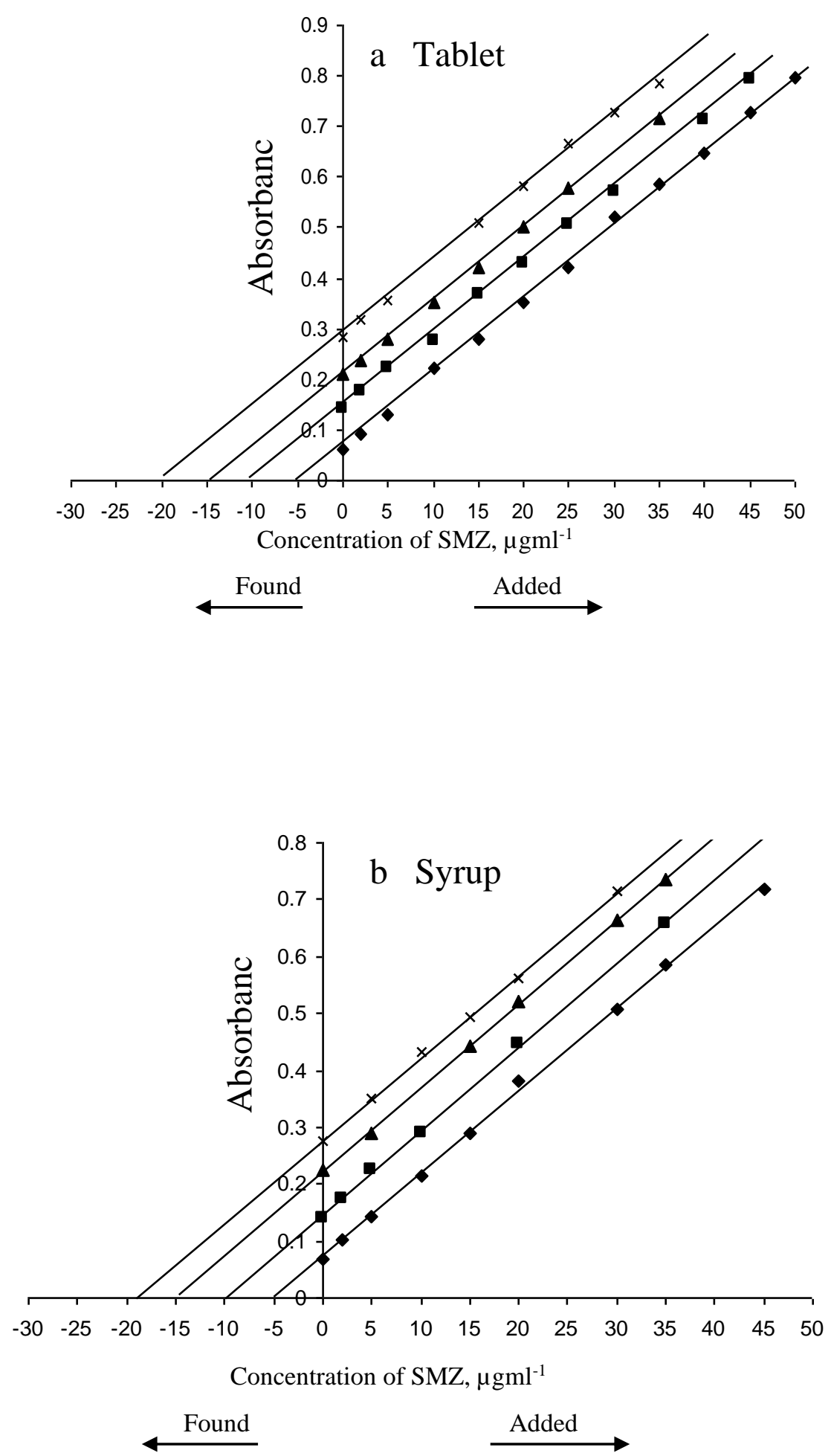

Fig.7: Standard addition plots for the recovery of $5(\diamond), 10(\square), 15(\Delta)$ and $20(x)$ $\mu \mathrm{gml}^{-1}$ of SMZ in tablet (a) and syrup (b). 
Table 4: Assay of SMZ in pharmaceutical preparations using the proposed method and comparison with the standard addition method

\begin{tabular}{|c|c|c|c|c|c|c|c|c|c|}
\hline \multirow{2}{*}{$\begin{array}{c}\text { Pharmaceutical } \\
\text { preparation }^{\mathrm{a}}\end{array}$} & \multicolumn{4}{|c|}{ Direct method } & \multicolumn{4}{|c|}{ Standard addition method } & \multirow{2}{*}{$\begin{array}{c}\text { Certified } \\
\text { value } \\
\text { (mg) }\end{array}$} \\
\hline & $\begin{array}{c}\text { Drug } \\
\text { amount } \\
\text { present } \\
\left(\mu \mathrm{g} \mathrm{ml}^{-1}\right)\end{array}$ & $\begin{array}{c}\text { Recovery }^{\mathrm{a}} \\
(\%)\end{array}$ & $\begin{array}{c}\text { Drug } \\
\text { content } \\
\text { found } \\
(\mathrm{mg})\end{array}$ & $\begin{array}{c}\text { Average } \\
\text { recovery } \\
(\mathrm{mg})\end{array}$ & $\begin{array}{c}\text { Drug } \\
\text { amount } \\
\text { present } \\
\left(\mu \mathrm{g} \mathrm{ml}^{-1}\right)\end{array}$ & $\begin{array}{l}\text { Recovery } \\
(\%)\end{array}$ & $\begin{array}{l}\text { Drug } \\
\text { content } \\
\text { found } \\
(\mathrm{mg})\end{array}$ & $\begin{array}{c}\text { Average } \\
\text { recovery } \\
(\mathrm{mg})\end{array}$ & \\
\hline \multirow{5}{*}{ Tablet } & 5 & 96.68 & 386.72 & \multirow{5}{*}{393.48} & 5 & 96.00 & 384.00 & \multirow{5}{*}{393.29} & \multirow{5}{*}{400} \\
\hline & 15 & 100.73 & 402.92 & & 10 & 101.30 & 405.20 & & \\
\hline & 30 & 98.71 & 394.84 & & 15 & 94.94 & 389.76 & & \\
\hline & 40 & 97.36 & 389.44 & & 20 & 98.55 & 394.20 & & \\
\hline & 7 & 106.10 & 212.20 & & 5 & 99.60 & 199.20 & & \\
\hline \multirow{3}{*}{ Syrup } & 12 & 100.40 & 200.80 & \multirow{3}{*}{203.82} & 10 & 98.67 & 197.54 & \multirow{3}{*}{198.28} & \multirow{3}{*}{200} \\
\hline & 25 & 101.62 & 203.24 & & 15 & 97.60 & 195.20 & & \\
\hline & 45 & 99.52 & 199.04 & & 20 & 100.60 & 201.20 & & \\
\hline
\end{tabular}

${ }^{\text {a }}$ Average of three determinations.

\section{Conclusion}

The proposed method is sensitive (trace amounts can be determined), accurate (average recovery range $100.95 \%$ ), precise (RSD $\leq$ 1.06) and simple since it does not need neither temperature control nor solvent extraction step. Analysis of authentic samples containing SMZ showed no interference from common additives and auxiliary substances in general. Hence, this method could be considered for the determination of SMZ both in pure form and in pharmaceutical preparations.

\section{References}

1) Budavari S., O’Neil M. J., Smith A., Heckelman P. E. and Kinneary J. F.: The Merck Index. An Encyclopedia of Chemicals, Drugs and Biologicals. 12th ed., Merck Research Laboratories, Division of Merck \& Co., Inc. Whitehouse Station, NJ (1996).

2) Bax R., Mullan N. and Verhoef J., (2000). The millennium bugsthe need for and development of new antibacterials. Int. J. Antimicrobial Agents 16; 51-59.

3) Shamsa F. and Amani L., (2006), Determination of sulfamethoxazole and trimethoprim in pharmaceuticals by visible and UV spectrophotometry, Iran. J. Pharm. Res., 1, 31-36

4) Dlane M. et al., (1979), Rapid assay for determination of trimethoprim and sulfamethoxazole levels in serum by spectrofluorometry, Antimicrobial. Agent Chemotherapy, 579-583.

5) Bedor D. C et al., (2008), Simultaneous determination of sulfamethoxazole and trimethoprim in biological fluids for highthroughput analysis: comparison of HPLC with ultraviolet and tandem mass spectrometric detection, J. Chromatogr. B Analyt. Technol. Biomed. Life Sci., 863, 46-54. 
6) Hişmioğulları E. Ş. and Yarsan E., (2009), Spectrophotometric determination and stability studies of sulfamethoxazole and trimethoprim in oral suspension by classical least square calibration method, Hacettepe Univ. J. Fac. Pharm., 29, 95-104

7) LeonardoS. et al., (2009), Simultaneous differential pulse voltammetric determination of sulfamethoxazole and trimethoprim on a boron-doped diamond electrode, Electroanalysis, 21, 14751480 .

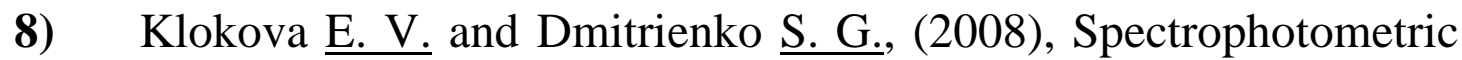
determination of sulfanilamides by a condensation reaction with pdimethylaminocinnamaldehyde, Moscow Univ. Chem. Bull., 63, 284-28.

9) Quanmin L. and Zhanjun Y., (2006), Spectrophotometric determination of sulfamethoxazole using sodium 1,2naphthoquinone-4-sulfonate as the chemical derivative chromogenic reagent, Chin. J. Anal. Chem., 34, 83-86.

10) Mohamed A. M., (1989), Spectrophotometric determination of some benzene sulfonamides with 7,7,8,8tetracyanoquinodimethane. J. Assoc. Off Anal. Chem., 72, 885-9.

11) Sinan R. and Al-Uzri W. A., (2011), Spectrophotometric method for determination of sulfamethoxazole in pharmaceutical preparations by diazotization-coupling reaction, J. Al-Nahrain Univ., 14, 9-16.

12) Al-Attas A.S., (2003), Charge transfer complex formation in spectrophotometric and conductometric determination of some sulfonamides, Saudi Pharm. J., 11, 141-145.

13) Kanchan p., Anupama A. and Neetu T., (2012), solid phase extractive spectrophotometric determination of some sulfa drugs, Asian J. Pharm. Clin. Res., 5, 222-226.

14) Nagaraja P., et al., (2002), A new, sensitive, and rapid spectrophotometric method for the determination of sulfa drugs, J. AOAC Int., 85, 869-874.

15) Nagaraja P., Naik S. D., Shrestha A. K. and Shivakumar A., (2007), A sensitive spectrophotometric method for the determination of sulfonamides in pharmaceutical preparations, Acta Pharm., 57, 333-42.

16) Hargis L.G., "Analytical Chemistry, Principles and Techniques", Prentice- Hall Inc., New Jersey. (1988) pp. 424- 427.

17) Alzoman N. Z. et al., (2013), Analytical study for the chargetransfer complexes of rosuvastatin calcium with $\pi$-acceptors, Molecules, 18, 7711- 7725. 